unconnected with the nest-cavity, but traversing the fortress from external runs, through which earth has been carried to heap over the nest. Fig. 2 shows a fortress of the most complicated type.

Except when in marshy soil, nearly every fortress has the aforesaid bolt-run, which leads upwards from the bottom of the nest, and thus outwards, without connection with the other tunnels. More rarely a down-shaft, which may be nearly a yard in length, descends obliquely from the nest. The use of these down-shafts is not apparent. Presumably it is in them that the collections of paralysed worms, supposed to be stored up by the mole as food, have been found. Such collections of worms are, however, regarded by the author as accidental.

The nest-cavity, which is about the size of a large cottageloaf, and worn smooth by friction, contains a ball of grass or leaves, or a mixture of both, by which it is completely filled. In the case of the English species, at any rate, no fur from the mole's body is used in lining the nest. Apparently a nest is never used for more than one season, but two or even three nests, generally one above the other, may be found in the same fortress, of which the newest is alone in use. In all cases it appears that the female makes a fortress and nest of her own in which to breed, this being usually less complex than that of her partner, and without a bolt-run. Whether previous to the breeding-time the female inhabits the same fortress as the male is doubtful, and it is not improbable that moles are polyandrous.

It is now demonstrated that the female produces only a single litter annually. The young are usually born between the middle of April and the latter part of June, after a gestation of four weeks; the number in a litter varies from two to six, three or four being usual. The number of teats in the female is eight, and not, as usually stated, six.

R. L.

\section{THE VISIBILITY OF ULTRA-MICROSCOPIC PARTICLES.}

$\mathrm{I}$ the course of an optical investigation of various shades of ruby glass, Messrs. Siedentopf and Zsigmondy devised a method of observing small particles of gold which closely approach molecular dimensions, and thus extending our range of molecular vision very considerably.

The ruby glasses, examined by the best ordinary microscopes, appeared perfectly homogeneous. But the authors reasoned that if the gold particles embedded in the glass were at such distances apart that a microscope could resolve them, they could be made visible even though their size should be a small fraction of the wave-length of visible light. The only condition was that the product of the specific intensity into the surface of the luminous particles and the square of the sine of the effective angle of illumination should be greater than the inferior limit of the sensitiveness of the human eye. The problem is thus reduced to that of the visibility of a fixed star. What is seen is, of course, a diffraction disc, and that is all we can hope to see, but the authors indicate a means of determining the true size and weight of the particles seen.

It is essential that all disturbing side-lights should be avoided. The authors threw a beam of sunlight through a condenser on a slit 0.05 to $0.5 \mathrm{~mm}$. wide, and an image of the slit was produced in the field of vision by a telescope lens and a collimator with a reduction of 36 diameters. The diffraction discs seen in the ruby glass had an average apparent diameter of I mm., while their real diameter, calculated from the quantity of gold present and the number of particles counted in unit volume, was $0.02 \mu$. on the average. This gives a magnification of 50,000 diameters The utmost limit to which the magnification can be pushed by this method is about 150,000 diameters, or $6 \mu \mu$. The average diameter of a molecule being $0.6 \mu \mu$., it cannot be seen, even as a diffraction disc, unless its specific luminosity were ten times that of the solar molecules, or the sensitiveness of the eye were greatly increased. The cumulative effects used in photography may be resorted to, but the authors do not mention that possibility.

1 Abstract of a paper by $\mathrm{H}$. Siedentopf and R. Zsigmondy (Annalen der Physik, No. 1, 1903, pp. $\mathrm{x}-39$ ).

$$
\text { No. } 1738 \text {, vOL. } 67]
$$

\section{UNIVERSITY AND EDUCATIONAL INTELLIGENCE.}

OXFORD.-A meeting of the teachers of natural science was held in the examination schools last Saturday to hear the views of a deputation of the Association of Public School Science Masters on the subject of entrance scholarship examinations. It was agreed that two principal subjects should be offered in scholarship examinations, and a suggestion was made that the subjects should be selected from physics, chemistry, botany, zoology and geology. The meeting was divided in opinion as to whether botany and zoology should form one group or two. With regard to the recommendation of the deputation that candidates not offering chemistry and physics should be given an elementary paper in these subjects, the meeting was unanimous as to the desirability of this course, and further suggested the addition for those candidates of a practical examination in elementary, chemistry and physics, which should not be confined to qualitative analysis.

Cambridge.-At a conference held on rebruary 7 between representatives of the Association of Public School Science Masters and the college tutors in natural science, the following recommendations in regard to the college examinations for entrance scholarships and exhibitions were provisionally agreed to:-(I) That the science part of the examination should consist of: (I) Papers and practical work in not. more than six subjects, namely, (I) physics, (2) chemistry, (3) geology, (4) the natural history of plants, (5) zoology, (6) the elements of botany and zoology, it being understood that no candidate may take the subject (6) if he take either of the subjects (4) or (5). Of these six subjects candidates must offer not more than two. (2) Candidates who take subjects (3), (4), (5) or (6) should be required to take an elementary paper in physics and chemistry. (3) Candidates who take subject (I) should be required to take an elementary paper in mathematics.

The vacancy at Caius College, caused by the death of Dr. N. M. Ferrers, F.R.S., has been filled by the election of the Rev. E. S. Roberts, senior tutor to the mastership.

The Gilbey lecturer in agriculture will give this term a course of lectures on small holdings and allotments in the Chemical Theatre, on Fridays, at 5.

A REPORT of the Committee of Privy Council in favour of the petitions of the Liverpool University College and Owens College, Manchester, for charters of incorporation as independent universities, was submitted to the King in Council on Monday and approved by him. The decision will be received with pleasure by all who are interested in the development of higher education in this country. It is essential that we should have more universities if we are to march with the times. Regional universities are not known in any civilised country, and only end in examinations and the destruction of real teaching and research. In the report published in Tuesday's Times, the committee expresses the opinion that as the step involves issues of great moment, and as the effect of the multiplication of universities ought not to be lost sight of, the authorities of the Yorkshire College at Leeds should have the opportunity of submitting a draft charter incorporating a University in Yorkshire before the draft charters sought are finally settled, and that the institutions concerned should be invited to consider in greater detail not only the points on which joint action is desirable, but also the methods by which it can best be secured. The committee also considers that special rights of inspection should be reserved to the King as Visitor, and that careful provision should be made in the charters to secure an effective voice to external and independent examiners in all examinations for degrees.

DR. D. J. Cunningham, F.R.S., professor of anatomy in Dublin University, has been unanimously elected to succeed Sir William Turner in the chair of anatomy at Edinburgh.

REUTER reports that it has been decided to create a chair of commercial science, with a special faculty, in the University of Zurich, which is the first on the continent to establish such a chair. 
THF: Duke of Devonshire will lay the foundation stone of the new technical institute and public library for Eastbourne on Saturday, April 25. The Duke has presented a site valued at $10,000 l$.

DR. ARTHUR DENDY has resigned the chair of biology in the Canterbury College (Christchurch, New Zealand), in order to go to the Cape of Good Hope as professor of zoology in the South African College, Cape Town, Cape Colony.

As an instance of the thorough manner in which educational problems are taken up in America, an announcement made by the Lahore correspondent of the Pionecr Mail is interesting. It appears that the University of Chicago has commissioned Mr. Alleyne Ireland to make a tour of the European dependencies in the East with a view to deliver a series of lectures on "Management of Tropical Colonies." He has already visited Hong Kong, Borneo, Singapore, and is now in India, though only as a tourist. He is devoting his attention for the present to European dependencies in Asia other than India.

Ar the last monthly meeting of the Pharmaceutical Society of Ireland, the following resolution was adopted:-That, in connection with the appointment of teachers of chemistry under the Department of Agriculture and Technical Instruction, the council take steps to ascertain the requirements of the Department, with the view of having their certificates accepted as qualifying their licentiates for the appointments. This resolution may lead to a modification of the course of instruction in the Irish Pharmaceutical Society's School of Chemistry which will make it possible for the licentiates of the school to qualify as teachers of chemistry in the Irish intermediate schools.

REFERENice to the Education Bill for Iondon was made in the King's speech delivered by His Majesty at the openjng of the new Session of Parliament on T'uesday. words used in the speech to the Commons were:-" Proposals will be submitted to you for completing the scheme of educational reform passed last Session by extending and adapting it to the metropolitan area." It is believed that the central authority for education in this area will be the County Council, but administrative details will be left in the hands of the borough councils to a greater extent than is the case with the local authorities under the extra-metropolitan Act of last year.

THE current number of the Library summarises, in a conrenient tabular form, Mr. Carnegie's gifts to libraries and other educational institutions down to November 30 of last year. From these tables it is seen that England and Wales have benefited to the extent of $376,100 l$, this amount including a donation of 50,1000 . to the University of Birmingham and one of $13,000 l$. to the Iron and Steel Institute. Ireland has received $100,600 \mathrm{l}$. and Scotland 2,479,250l. The princely gift to Scotland includes the endowment fund of $2,000,000 l$. for Scottish universities, a sum of $100,000 l$. given to the Technical School at Galashiels, 38,0ool. to the Dunfermline Technical School, and 50,000l. to Aberdeen University. Canada has received 954,000 dollars, which represents the total sum given for the foundation of thirty-one public libraries. I ibraries and other educational institutions in the United States have reaped the advantage of $\mathrm{Mr}$. Carnegie's munificence to the enormous extent of $212,882,173$ dollars. The Fayette Upper University, Iowa, has received 225,000 dollars; the I,ouisville Polytechnic Institute 125,000 dollars; the Carnegie Laboratory of New York City 600,000 dollars; the Pennsylvania State College I00,000 dollars; the Carnegie Institute at Pittsburg 7,250,000 dollars; the Polytechnic School of the same place, as an endowment, two million dollars; and the National University of Washington ten million dollars. Cuba, too, has shared in the same lavish generosity, for Havana has received 250 , 000 dollars and Matanzas 2000 dollars.

\section{SOCIETIES AND ACADEMIES.}

LONDON.

Royal Society, January 22.-"Solar Eclipse of 1900 May 28. General Discussion of Spectroscopic Results." By J. Evershed, F.R.A.S.

The spectra discussed in this paper were obtained near the southern limit of total eclipse, and include, therefore, NO. I 738 , VOL. 67 ] the chromospheric spectrum of the south polar region of the sun, as well as the same spectrum in mid-latitudes.

The coincidence in position of the vast majority of the bright lines with the Fraunhofer dark lines is shown to be exact within the limits of the measures. But the relative intensities of the bright lines of any one element, although in generil agreement with those of the corresponding dark lines, are not in all cases the same, and those lines which are exceptionally strong in the chromospheric spectrum are mostly lines which are enhanced in the spark spectrum of the element.

All the more prominent enhanced lines of iron and titanium as determined by Sir Norman Lockyer are found to coincide with strong lines in the chromosphere, and these lines are found to be equally prominent in the south polar region and in mid-latitudes.

The abnormal intensity of the enhanced spark lines in the flash spectrum is explained by assuming a continuous circulation of the solar gases in a radial direction, the highly heated ascending gases, emitting the enhanced lines, giving the predominant features to the chromospheric spectrum, whilst the cooler, more diffused gases, slowly subsiding, determine the character of the absorption specirum.

The entire chromosphere is supposed to consist of innumerable small eruptions or jets, of a similar nature to the so-called metallic prominences, which latter are only the more pronounced manifestations of the same eruptive agencies.

Evidence for this is found in the characteristic features of the chromosphere, and in the structure of many of the Fraunhofer lines, which show emission lines underlying the narrow absorption lines. These ill-defined bright lines in the normal solar spectrum are displaced towards the violet, indicating a strong uprush of the hotter gases, whilst the narrow dark lines would appear to indicate a slow and uniform descent of the absorbing gases.

The finat conclusion is that the spectrum of the chromosphere represents the emission of both ascending and descending gases, and the Fraunhofer spectrum represents the absorption of the descending gases only.

"P'reliminary Note on the Relationships between Sunspots and Terrestrial Magnetism." By Dr. C. Chreo, F.R.S.

This deals with results of magnetic declination, inclination, horizontal and vertical force obtained at Kew Observatory (National Physical Laboratory) on magnetically quiet days from 1890 to 1900 . The ranges of the diurnal inequalities are compared with the sun-spot frequencies as calculated by Wolfer Between the diurnal range $R$ of an element and the sun-spot frequency $S$, a linear relation $R=a+b S \ldots$ (1) is as sumed, $a$ and $b$ being taken as constants for any given month of the year, but as fluctuating from one month to another. The values of $a$ and $b$ have been calculated for each month of the year from the eleven years' data by least squares. The preliminary note gives the mean values for "winter," "equinox" and "summer"-including four months in each season-and the mean for the twelve months. The constants $a$, representing the values of the range for zero sun-spot frequency, are smallest in winter and largest in summer. The constants $b$ are in the case of the declination, inclination and horizontal forcewhere the sun-spot connection is more clearly marked than in the vertical force--largest at the equinox. The variation of $b$ with the season appears closely the same for the three mag. netic elements specified. On the average of the three, the proportional values obtained for $b$ are, winter 82 , equinox II 5 , summer 103. Whilst $b$, considered absolutely, appears largest at the equinoxes, the sun-spot influence (or rather correlation) is relatively much most important in winter. During the eleven years considered, Wolfer's mean sun-spot frequency was $4 \mathrm{I} \cdot 7$; so that, according to (I), $I+4 I \cdot 76 \div a$ represents the ratio of the range answering to mean sun-spot frequency to the range answering to absence of sun-spols The average values of $4 I^{\circ} b+a$ for the declination, inclination and heriznntal force in winter, equinox and summer respectively were $0.57,0.38$ and 0.27 . The means of the twelve-monthly absolute values found for $b$ were, declination $\mathrm{O}^{\prime} \mathrm{O} / \mathrm{I}$, inclination $\mathrm{O}^{\prime} \mathrm{OI} 3$, horizontal force $0.19 \gamma$ and vertical force $0.03 \gamma$, where $\gamma$ represents I $\times 10^{-5}$ C.G.S. Reference is made to work by Balfour

Stewart, Ellis, Wolfer, Rajna and Angot, and the legitiniacy of the use of Wolfer's table of sun-spot frequencies is considered. 